\title{
Efectos psicológicos de la literatura en mujeres de un club de lectura en Medellín'
}

\author{
Nicolás Ignacio Uribe Aramburo² \\ Universidad de San Buenaventura, Medellín (Colombia)
}

Recibido: 21/02/2019 Aceptado: 19/11/2019

\begin{abstract}
Resumen
Objetivo. Evidenciar el efecto psicológico de un club de lectura, el cual promueve el desarrollo personal (incluidos los aspectos cognitivos), los procesos de simbolización, la resignificación de la historia de vida, el reconocimiento y el empoderamiento de las mujeres y sus derechos en los contextos familiar, comunitario, político y social. Método. Se empleó la teoría fundamentada y estrategias de recolección, como la entrevista semiestructurada y los grupos focales, para el análisis de datos cualitativo. Resultados. Los hallazgos revelaron siete efectos psicológicos derivados de la experiencia de un club de mujeres que leen, escriben y dialogan acerca de grandes obras literarias producidas por escritoras latinoamericanas, sus roles y representaciones estéticas sobre la mujer en la sociedad, así como temas con el ser mujer, la desigualdad, la marginación y la sensación de soledad. Conclusión. Se adoptó la última perspectiva de la psicología social y se retomaron los conceptos de simbolización y soborno estético para establecer una analogía entre las funciones de este club y las psicoterapias; de esta manera, fue posible dar cuenta de la importancia de estos espacios culturales en el desarrollo personal, comunitario, político y social de las mujeres que integran el club de lectura.
\end{abstract}

Palabras clave. Literatura, simbolización, psicoterapia, mujer, teoría fundamentada.

\section{Psychological Effects of a Reading Club on Women in Medellín}

\begin{abstract}
Objective. To explore and demonstrate the roles of a reading club in the promotion of personal development (including cognitive aspects), the processes of symbolization, the re-signifying of life history, the recognition and empowerment of women and their rights in the family, community, political and social context. Method. The Grounded theory, was used; strategies of collection included a semi-structured interview and focus groups, for qualitative analysis of the data. Results. The study identified seven psychological effects that were derived from the participation in a club of women who read, wrote and discussed great literary works produced by Latin American writers, dealing with roles and performances of women in society. The questions of being a woman, inequality, marginalization and a sense of loneliness were also addressed in the club. Conclusion. The

\footnotetext{
Artículo producto del proyecto de investigación titulado "Construcciones estéticas. Una experiencia a partir de la narrativa biográfica en un club de lectura de la ciudad", avalado y financiado por la Universidad de San Buenaventura, mediante Acto administrativo \# M3833, del 31 de agosto de 2017.

2 Magíster en Investigación Psicoanalítica. Correo de correspondencia: nicolas.uribe@usbmed.edu.co
} 
last perspective of social psychology was adopted and the concepts of symbolization and aesthetic bribery, were used to establish an analogy between the functions of this club and psychotherapies. In this way, it was possible to account for the importance of these cultural spaces in the personal, community, political and social development of the women who make up the reading club.

Keywords. Literature, symbolization, psychotherapy, women, grounded theory.

\title{
Efeitos psicológicos da literatura em mulheres de um clube de leitura em Medellín
}

\begin{abstract}
Resumo
Escopo. Explorar e evidenciar o efeito psicológico de um clube de leitura, o qual promove o desenvolvimento pessoal (incluídos os aspetos cognitivos), os processos de simbolização, a resinificação da história de vida, o reconhecimento e o empoderamento das mulheres e seus direitos nos contextos familiar, comunitário, político e social. Metodologia. Foi utilizada a teoria fundamentada, juntamente com estratégias de recoleção, como a entrevista semiestruturada e os grupos focais, para e análise qualitativo dos dados. Resultados. As descobertas revelaram sete efeitos psicológicos derivados da experiência de um clube de mulheres que leem, escrevem e dialogam sobre grandes obras literárias produzidas por escritoras latino-americanas, seus roles e representações estéticas sobre a mulher na sociedade, assim como temas com o ser mulher, a desigualdade, a marginação e a sensação de soledade. Conclusão. Foi adotada a última perspetiva da psicologia social e foram retomados os conceitos de simbolização e suborno estético para estabelecer uma analogia entre as funções deste clube e as psicoterapias; de este jeito, foi possível dar conta da importância destes espaços culturais no desenvolvimento pessoal, comunitário, político e social das mulheres que integram o clube de leitura.
\end{abstract}

Palavras-chave. Literatura, simbolização, psicoterapia, mulher, teoria fundamentada.

\section{Introducción}

La lectoescritura no solo promueve el desarrollo del pensamiento y la evolución de las estructuras cognitivas (Piaget, 1971; Wittmann, 2001), sino que, además, aporta a la formación de la personalidad y los valores éticos y morales de los niños y los adolescentes (Bettelheim, 1977). En el marco del desarrollo evolutivo, es importante que estas poblaciones puedan acceder a este tipo de actividades que preparan a los sujetos para el futuro ejercicio de la ciudadanía. Es por ello que estas actividades (lectura) forman parte de los procesos que se desarrollan al interior de las instituciones educativas, pues se reconoce su valor formativo, que no se reduce al aprendizaje de conocimientos académicos, también incluye la lectura de obras literarias y su análisis mediante informes de lectura (escritura) que socializan, en los cuales se despliegan los procesos cognitivos y las funciones simbólicas para representar la realidad propia y la social, promoviendo el desarrollo humano (Chartier, 1993; 2000; 2001).
Sin embargo, poco se ha reconocido la influencia de estas actividades en los adultos, razón por la cual, en esta investigación se estudian los efectos que pueden generar los procesos de lectoescritura y diálogo al interior de un club de mujeres que se reúnen en espacios públicos, ajenos a los centros y programas educativos de todo tipo, para compartir las impresiones que les generan las grandes obras literarias (Ovejero, 2012).

En la psicología social, las novelas se toman como fuente de información, ya que revelan las dinámicas sociales de diversas épocas históricas, por ello se analizan los usos de la literatura y la novela. En las grandes novelas de los siglos XIX y $X X$ se describen dinámicas sociales que ocurren en las grandes ciudades, a la par que se relatan historias de vida individuales (Pérez-Álvarez, 1992), de modo que se recurre, según Ovejero (2012), a "la literatura para entender al hombre moderno" ( $p$. 10).

Con la revolución industrial, en el siglo XVIII, se presentó un cambio radical en la industria del 
libro y, por ende, se generó un público masivo para la lectura (Wittmann, 2001). Pero en el siglo XIX, el público lector empezó a ser más diverso, las lecturas se escogían de forma más libre y eran más amplios los intereses de los nuevos lectores, incluidos niños y mujeres de la burguesía acomodada. Sin embargo, la lectura todavía seguía siendo una forma de control social, para inculcar ideologías que permitieran la dominación social (Chartier, 2001; Ovejero, 2012).

Ahora, expertos como Neira (2014) coinciden en que "el psicoanálisis, la psicología analítica y la psicología humanista han hecho uso de la literatura de una u otra manera" (p. 6), pues el punto de interés de la relación entre psicoterapias y literatura radica en el hecho de que "la psicología pueda hacer uso de obras literarias con fines terapéuticos y que la literatura (...) haga uso de la psicología en la crítica literaria" (p. 7).

Este autor también ha señalado que, específicamente, en el proceso creativo y en la lectura de obras literarias se halla un "intento por evadir la realidad por parte del artista y del lector" (p. 7), y además que "ambos buscan negar la realidad y encontrar un refugio para su espíritu. La literatura proporciona pues un escape a sus cuitas, y les permite transformar el estado en que se encuentran las cosas" (p. 17). Al interior de la ciencia psicológica y el psicoanálisis se han realizado investigaciones que establecen correlaciones entre la literatura y la psicología, y más concretamente las psicoterapias, con distintos objetivos, pues la relación entre este tipo de expresión artística y la ciencia psicológica puede ser estudiada desde diversas perspectivas (Neira, 2014; Ovejero, 2012).

Algunos autores (Freud; 1905a; 1907; Jung, 1982) han estudiado los mecanismos y las funciones psíquicas implicados en el acto creador del artista; otros (Neira, 2014; Ovejero, 2012) se han enfocado en el análisis de las obras literarias para conocer la personalidad del artista y su historia de vida. También, desde la psicología social, se han estudiado las obras literarias para conocer las dinámicas sociales de una época particular de la historia de la humanidad. Mientras que otros estudian los efectos de la obra literaria en el lector. En la antigüedad, los griegos fueron pioneros en analizar los efectos de la obra teatral en los espectadores. Este fenómeno es retomado por Freud (1905a), al comparar las creaciones literarias de los poetas con las fantasías, los sueños y los juegos de los niños.
Al respecto, Ovejero (2008; 2009; 2012) y Neira (2014), investigadores de la psicología social, coinciden al señalar la importancia del "estudio de los efectos de la lectura de las obras literarias, es decir, la forma en que transforman el comportamiento y la forma de pensar de los lectores" (Neira, 2014, p. 4), lo cual es relevante para nuestros intereses. Este autor sostiene que "esta clase de lecturas colaboran en la formación del ser humano, facilitándole el desarrollo de una psicología intuitiva que le será útil para afrontar la vida" (p. 4).

Por lo anterior, en este artículo se describe y analiza la experiencia literaria de un grupo de mujeres de la ciudad de Medellín (Colombia), que se reúnen en un club de lectura conformado por ellas para leer, escribir y conversar acerca de grandes obras escritas por mujeres latinoamericanas. Estas describen las condiciones socioculturales de las mujeres y su subjetividad, haciendo una crítica a los estereotipos e imaginarios sociales tradicionales. Esto con el objetivo de mostrar los efectos que ejercen los procesos de lectura, escritura y diálogo que promueve el club en las participantes y señalar la importancia que tienen estos espacios culturales y grupales en el desarrollo personal (incluidos los aspectos cognitivos) y comunitario, los procesos de simbolización, la resignificación de la historia de vida, el reconocimiento y el empoderamiento de las mujeres y sus derechos en los contextos familiar, comunitario, político y social, los cuales deberían ser reconocidos y promovidos en mayor medida por el Estado colombiano.

Para estudiar algunos de los efectos psíquicos que se derivan de los procesos de lectura, escritura y diálogo entre los miembros del club de lectura, se adoptó la última perspectiva de la psicología social, a través del análisis de frases extraídas de las entrevistas y los grupos focales realizados, en las que se observó tanto el efecto de la obra literaria sobre la identidad del grupo y sus dinámicas como la propia vida de cada una de las mujeres que integran el club de lectura (Taylor y Bogdan, 1984).

\section{Método}

\section{Diseño}

Se utilizó una metodología cualitativa, con el fin de conocer los aspectos subjetivos e intersubjetivos 
que se derivan de la experiencia lectora de las participantes en el estudio, cuyo diseño se basó en la teoría fundamentada. El alcance de la investigación fue descriptivo, dado que la intención era conocer una realidad social y describir fenómenos psicosociales (Serbia, 2007; Taylor y Bogdan, 1984; Vasilachis, 1992; Velasco y Díaz, 1997).

\section{Participantes}

Las participantes fueron escogidas por muestreo no probabilístico, por conveniencia. Los criterios de inclusión fueron los siguientes: (a) ser miembro del club Litera, (b) ser mayor de edad, (c) estar dispuesta a participar voluntariamente en la investigación, y (d) ser mujer. Debido a que el diseño fue cualitativo, no se construyó una muestra representativa del grupo (Serbia, 2007; Vasilachis, 1992). Se seleccionaron cinco integrantes que cumplieron con los criterios de inclusión.

\section{Instrumento y Procedimiento}

Se utilizó la entrevista semiestructurada de forma individual, entre tanto, los grupos focales se realizaron con todo el grupo de mujeres miembros del club. Las herramientas fueron aplicadas entre enero y julio de 2018. Las entrevistas y los grupos focales tuvieron una duración variable, entre 40 y 90 minutos, y se llevaron a cabo en bares del centro de la ciudad de Medellín, e implicaron el uso de grabadoras para registrar la información. Se elaboraron formatos guía para las entrevistas individuales y para los grupos focales.

Cada una de las participantes aceptó colaborar voluntariamente y firmaron los respectivos consentimientos, luego de que se les explicara claramente la inexistencia de riesgos para su integridad personal, para lo cual se cumplió con los protocolos éticos de la Declaración de Helsinki 1975, los lineamientos éticos de la Resolución 8430 de 1993 del Ministerio de Salud de Colombia, así como del Comité de Bioética de la Universidad de San Buenaventura (Acto Administrativo M 3833, del 31 de agosto de 2017), por lo cual no existió conflicto de intereses entre el grupo de investigadores y las participantes.

Las entrevistas fueron transcritas por tres auxiliares de investigación, estudiantes del programa de Psicología de la Universidad de San Buenaventura de Medellín. Luego fueron ingresadas en el software Atlas.ti para procesar los datos (Serbia, 2007; Taylor y Bogdan, 1984; Vasilachis, 1992; Velasco y Díaz, 1997).

Inicialmente, uno de los investigadores contactó a una integrante del club, que actuó como "portera"; luego este contactó a los demás investigadores con otros miembros del club de lectura (Taylor y Bogdan, 1984; Velasco y Díaz 1997).

Por último, se hizo una interpretación de estos hallazgos desde la psicología social de Ovejero (2007a) y algunas teorías psicoanalíticas (específicamente la teoría del soborno estético) que permiten realizar aproximaciones novedosas a las relaciones entre literatura y psicología, las cuales son de utilidad para los psicólogos en el ejercicio de su profesión tanto en el ámbito clínico como en el investigativo, pero también en el educativo y social comunitario.

\section{Análisis de datos}

En el software se descontextualizó la información que se ingresó, según el orden establecido en el formato guía de entrevista individual y grupo focal, pues de acuerdo con el método de la teoría fundamentada, a partir de los comentarios y dichos que aparecen en las entrevistas y grupos focales se aislaron frases significativas que dan cuenta de los efectos que produce la experiencia de leer, escribir y dialogar en este club de mujeres, a las cuales se les asignó un código y fueron agrupados en árboles de familias (Taylor y Bogdan, 1984; Vasilachis, 1992; Velasco y Díaz, 1997).

Se crearon 130 códigos en total, los cuales fueron agrupados en 11 árboles de familias que presentaban las siguientes características específicas: (a) club, (b) conciencia de mujer, (c) escritura, (d) espacio de encuentro, (e) espacio terapéutico, (f) género, ( $g$ ) lectura, (h) momentos del club, (i) preguntas que movilizan, (j) relato autobiográfico, y (k) sentimiento político.

Finalmente, con base en este agrupamiento, se establecieron siete categorías emergentes: (a) metodología e identidad grupal; (b) elección de las lecturas; (c) desarrollo intelectual; (d) vínculos, procesos simbólicos y afectivos; (e) acompañamiento y estética; (f) resignificación de la historia; y (g) posición política. 


\section{Resultados}

Se analizaron las características de cada categoría emergente y su relación con el nombre de cada una, dado que, según la metodología empleada en la teoría fundamentada, la categorización axial se efectuó para ordenar las temáticas, identificando los temas comunes que aparecían en los discursos de forma desordenada. A partir del discurso de las mujeres del club en las entrevistas y talleres, se conformaron las categorías, las cuales se presentan a continuación con su respectiva descripción.

Categoría 1. Metodología e identidad grupal: Se encontró que el impacto de la lectura en las integrantes del club empieza desde experiencias previas en otros clubes de lectura, de las cuales extrajeron elementos para crear la metodología, convirtiéndose en la base de las dinámicas y la identidad grupal, de esa manera, la experiencia lectora pasada se articula con la presente.

Categoría 2. Elección de las lecturas: Las experiencias lectoras pasadas ayudaron a elegir el tipo de lecturas del club, pues en común acuerdo eligieron un tipo de literatura particular (escrita por mujeres sobre mujeres), lo cual muestra la influencia de los procesos grupales sobre las motivaciones individuales, pero también de la identidad grupal, similar a lo que ocurre en la psicología de las masas, en la que los individuos se homogenizan (Freud, 1921).

Categoría 3. Desarrollo intelectual: Se evidenció un desarrollo de los procesos cognitivos y el nivel intelectual de sus participantes, pues la lectura y el análisis conjunto de las novelas favoreció el despliegue de estas capacidades, a partir de la articulación de la interpretación intersubjetiva que se hace de las ficciones presentadas en las obras.

Categoría 4. Vínculos, procesos simbólicos y afectivos: El despliegue de procesos afectivos, simbólicos y cognitivos se produjo simultáneamente, pues el diálogo acerca de las impresiones causadas en cada participante, a partir de la lectura individual, generó efectos emocionales que repercuten en las dinámicas grupales y permiten cohesionar al grupo. Estos procesos se despliegan a partir de las temáticas y los personajes de las obras literarias escritas por mujeres, los cuales representan problemáticas propias de las mujeres, especialmente latinoamericanas.
Categoría 5. Acompañamiento y estética: La experiencia reveló que la sensación de compañía que se experimenta al ser parte del club, efecto semejante a lo que ocurre en el proceso de catarsis, de desahogo emocional que se produce en las psicoterapias, tanto individuales como grupales, permitió articular las vivencias de los personajes ficticios con sus propias vivencias, en las cuales la soledad y la tristeza fueron factores comunes que hicieron posible la identificación entre ellas, a pesar de las diferencias individuales. Aquí se destaca la función de lo estético, que permite abordar temáticas que normalmente generan displacer y suelen ser evitadas. Así, aunque las lecturas y diálogos trataban acerca de la desigualdad social, la exclusión, la marginalidad a la que han sido sometidas las mujeres durante la historia de la civilización machista y patriarcal, la experiencia grupal produjo efectos placenteros.

Categoría 6. Resignificación de la historia: La más amplia y significativa. Se articula a las categorías anteriores, pues la reflexión sobre la experiencia propia acerca de temas referidos a situaciones de marginación social, permitió resignificar la historia de vida propia y asumir una postura ética frente a esas situaciones de abuso del pasado, a partir de las identificaciones creadas entre las mujeres del club, las protagonistas de las novelas y las escritoras de esas novelas.

Categoría 7. Posición política: Se evidenció la emancipación y la adopción de posiciones políticas que favorecieron el desarrollo grupal, social y personal, promovió la crítica social y el empoderamiento frente a una sociedad machista que perpetúa la desigualdad y la marginación de las mujeres, encasillándolas en el clásico rol de ama de casa, madre y esposa, restando posibilidades de autonomía, desarrollo personal y profesional.

Ahora bien, la lectura y la escritura cobraron valor al ser articuladas con el uso de la palabra, con el diálogo que se produce en el encuentro, pues no solo se escucha lo estrictamente referido a la obra literaria, sino también los comentarios y dichos de las participantes acerca de sus propias vivencias, que no resultaban inadecuados por ser íntimos, ya que la dinámica del club daba importancia a la experiencia de vida y la perspectiva del otro.

A partir de las categorías establecidas, basadas en el discurso de las mujeres del club en las 
entrevistas y talleres, se realizó el análisis de las respuestas textuales aisladas, para dar cuenta de la importancia de estos espacios culturales en el desarrollo personal, comunitario, político y social de las mujeres.

Categoría 1. Metodología e identidad grupal: Las integrantes del club crearon la metodología de trabajo del club Litera, con base en experiencias previas en otros clubes de lectura. Al respecto, una de ellas expresó que:

Se construyó la metodología a partir de ejercicios (...) con otros grupos de la ciudad (...). Éramos un grupo de personas que teníamos experiencia en la lectura y nos reuníamos a pensar el tema metodológico (...). No somos mujeres tradicionales en esa metodología (...). Son ideas muy flexibles, muy frescas e innovadoras (...). No hay una exigencia en asistencia, ni en lecturas, nosotras somos muy flexibles (...). Podés ir así sea para escuchar, para que nos encontremos... (participante 1 [p1]).

Categoría 2. Elección de las lecturas: Se observó que eligen principalmente temas de mujeres, representados por personajes femeninos creados por grandes escritoras latinoamericanas. Estas elecciones estaban influenciadas por la experiencia lectora previa. La siguiente cita evidencia que la identidad grupal se configuró desde las experiencias pasadas de cada una de las integrantes en otros grupos, tal como manifestó una de ellas:

Ser parte de Diáfora fue un momento muy importante en mi vida, en relación con la lectura, porque fue ahí donde yo pude desenvolverme (...). Estar en Litera creo que ha definido la mayoría de mis lecturas (p. 1).

Categoría 3. Desarrollo intelectual: Las actividades en el club de lectura promueven el desarrollo de los procesos cognitivos y el nivel intelectual de sus participantes; así lo señaló una de ellas:

Ir subiendo ese nivel, pero yo creo que es sin exigirse, es por la experiencia misma que tiene el grupo (p. 3).

La misma integrante comentó sobre lo que siente cuando se ausenta y vuelve a asistir:

Como que perdí nivel (...) quizás no alcanzar a leer y a estar al nivel de las que uno sabía que se habían esmerado (...). Perdí nivel porque la capacidad para argumentar frente al análisis de las lecturas va evolucionando mucho, he notado, en el discurso de las mujeres que han estado de manera más constante en club, un crecimiento impresionante (p. 3).

Como se pudo constatar, uno de los efectos directos de la experiencia lectoescritora grupal es su incidencia sobre los procesos cognitivos, lo que favorece el despliegue de las capacidades intelectuales generadas por la articulación de la interpretación intersubjetiva de las ficciones presentadas por las grandes autoras de las obras literarias escogidas por este grupo de mujeres que conforman el club.

Categoría 4. Vínculos, procesos simbólicos y afectivos: Fue evidente que los procesos cognitivos, simbólicos y afectivos emergieron de forma simultánea. Por ello, a partir de la lectura individual, se produjeron efectos sobre las dinámicas grupales que se entrecruzan con la identidad individual y psicosocial de cada una de las participantes. Esta articulación de factores cognitivos y emocionales relacionados con el diálogo sobre la obra, pero también acerca de la identidad propia y la representación de la realidad, se pudo observar en las apreciaciones de una de las integrantes:

Una apropiación frente ese ser mujer, frente a esas diferentes maneras de percibir la realidad de esas mujeres en esos contextos, citan a las autoras de manera constante, me parece que tiene un nivel que cualquier persona no necesariamente soporta estar en el club, precisamente por la calidad y el nivel de las participantes (p. 3).

En las entrevistas, fue notable que los procesos afectivos y cognitivos se despliegan a partir de las temáticas y los personajes de las obras literarias escritas por mujeres que ilustran problemáticas de las mujeres latinoamericanas, siendo importante el aporte a la reconfiguración de la identidad propia en las integrantes del club, a partir de los procesos de identificación que se generan en el diálogo que permite una interpretación conjunta de las obras y la propia realidad. Así lo expresó una de las participantes:

La profundidad la da la interpretación particular de todas (...) con los clubes. Se hace más intenso vivir esa experiencia lectora, que termina amplificándose por ser algo compartido (p. 2). 
Aquí se hizo evidente la intersubjetividad que permite compartir algunos aspectos de la realidad social, tomados de la experiencia lectora y articulados a la historia de vida singular, siendo las problemáticas femeninas el factor común en el diálogo que se produce en estos encuentros.

Categoría 5. Acompañamiento y estética: Al ser parte de una actividad grupal, se experimenta una sensación de compañía y apoyo. Así, por ejemplo, refiriéndose a una novela, una integrante del club dijo que allí las mujeres buscaban una compañía en ese:

\section{(...) lugar donde se encuentran (p. 4).}

Luego comparó ese lugar de la novela con el club y afirmó que este tiene como objetivo:

Aglutinar personas con intereses comunes, que sería la lectura, y en ese sentido, es como un cohesionador social importante (p. 4).

Como cohesionador social, el club permite articular las vivencias de los personajes ficticios con sus propias vivencias, por ello cumple la función de promover el despliegue de los procesos afectivos de forma que no se generen sensaciones de displacer $y$, en cambio, puedan tratarse temáticas y situaciones acerca de la soledad y la tristeza de las mujeres y aun así los efectos psíquicos producidos sean de placer y bienestar. Sobre esto, una integrante comentó que:

La anécdota bella de este encuentro es que llegamos mujeres (...) (p. 1).

Aunque las temáticas sobre las que dialogan tratan acerca de la desigualdad social, la exclusión, la marginalidad a la que han sido sometidas las mujeres durante la historia de la civilización, que se ha caracterizado por el machismo y el patriarcado, la experiencia grupal produce efectos placenteros ligados a la dimensión estética, la cual permite reconfigurar la realidad intersubjetiva y, por ende, la identidad propia y la historia de vida individual, desde una actividad de la cual se disfruta. Así lo manifestó una de las participantes:

Es muy bonito porque (...) es también como romper esquemas (...) o sea, si estamos aquí es por un disfrute, por una profundización en esa vida y esa obra (...) le da a uno como otra perspectiva, para enlazar muy bonito (p. 1).
Por ello, al comentar acerca de una de las escritoras elegidas por ellas, una de las integrantes del club mencionó que:

Me acerqué con ella a la lectura de una manera muy bonita" (s. 1).

Al hablar sobre el tema del maltrato físico y psicológico ejercido en el proceso de crianza de una de las protagonistas de las novelas, la misma participante agregó que dicha lectura le ha permitido ser:

Una nueva mujer que sabe que la pedagogía del castigo, la pedagogía del miedo está abolida completamente desde nuestra forma de pensar, y siempre proponemos cosas muy bonitas, desde la comida, desde el espacio, desde las estéticas en las que nos encontramos (p. 1).

Por ello, una integrante dijo que una función del club es:

Poder, también, reconocerte (p. 5).

Esto debido a que los personajes de estas novelas constituyen modelos identificatorios que promueven la reestructuración del self (sí mismo), ya que, según una integrante del club, esos personajes ficticios serían referentes:

(...) frente a situaciones que he vivido (p. 5).

Categoría 6. Resignificación de la historia: La reflexión sobre la experiencia propia acerca de situaciones potencialmente traumáticas (como el maltrato físico y psicológico y la violencia intrafamiliar) tratados en las novelas, permitió resignificar la historia de vida propia y asumir una postura ética frente a esas situaciones de abuso del pasado, siendo importante el papel o función de lo estético (categoría 5).

En ese sentido, lo estético cumplió una función de facilitación de la rememoración implicada en el proceso catártico y simbólico. Al respecto, una integrante resaltó que en una experiencia lectora previa en otro club:

(...) el ambiente que se recreó y la estética que se recreó en esa casa, era bellísima (p. 5).

Este fenómeno del tratamiento de lo doloroso que genera sufrimiento, malestar y displacer a partir de la experiencia estética de lo bello, se evidenció también en una integrante que comentó que las novelas que leen les: 
(...) hacen muchas preguntas, entonces a veces las preguntas son tan fuertes y los temas que estamos tocando no son tan amenos (...) (p. 4).

Otro ejemplo de la identificación entre las mujeres del club y las mujeres protagonistas y las autoras de esas novelas, es el hecho de que en las dinámicas del club se incluyeron tanto elementos gastronómicos autóctonos de los países y regiones de los que provienen las escritoras como el deseo de reconocimiento. Así lo expresó una de las participantes:

Nos vinculaba mucho la comida (...) hacíamos comida después de que terminábamos un libro (...) es más que tuviera que ver con, por ejemplo, con Frida Kahlo, el guacamole (...) (p. 2).

Al describir las dinámicas grupales y sus costumbres, la misma integrante comentó que:

(...) un arroz con coco (...) cerramos un libro. En diciembre llegan las brisas, de Marvel Moreno, de la barranquillera, comimos patacón, pescado y ese arroz (...) (p. 2).

Retomando el problema del sufrimiento asociado a la condición de ser mujeres en el contexto social, reflejado en las novelas que leen en sus encuentros, el tema que insistía en sus experiencias grupales se refiere a la pregunta por el ser mujer:

(...) porque la pregunta por el ser mujer no termina con ninguno de los libros, es nuestra constante (...) mujeres que leen sobre mujeres (p. 1).

La misma integrante agregó que al leer estas autoras que han sido reconocidas no es fácil, ya que:

(...) ese tema de hacerse preguntas por el ser mujer no para (...), pero sí evoluciona todo el tiempo, o sea, las preguntas no son las mismas (p. 1).

Como puede verse, existe una identificación entre las integrantes del club con las escritoras de las novelas que leen y sus personajes femeninos, siendo el deseo de reconocimiento una constante. Además, esta participante mencionó que:

(...) en ese diálogo se descubren esas miradas increíbles, pues [las autoras son] asombrosas y eso enriquece demasiado el acercamiento ( $p$. $1)$.

De este comentario se deduce que es evidente el hecho de que la lectura de las historias novelescas "enriquece" la perspectiva propia individual respecto de la propia existencia. Por ello, la experiencia lectora del club promueve la autobservación, como en una psicoterapia grupal, tal como lo señaló la participante 1:

(...) todo eso ha estado atravesando mi vida por completo (...) la experiencia con otras (...) te enriquece (...) permite ampliar el espectro en cuanto a la comprensión de los textos (...) a la lectura de otros, a leer otras escritoras.

Otro comentario, en el que se articula la reflexión propia y la función de la escritura derivada de la lectura de las novelas apoya este punto de vista:

(...) al leerse a sí mismo, es decir, de manera biográfica, uno identifica cosas que de pronto no sabía que existían, o no se había dado cuenta de que tenía (...) yo creo que en ese sentido permite también la reflexión (p. 4).

Al respecto, otra integrante enfatizó sobre la importancia de las devoluciones que recibe en la experiencia grupal:

Las interpretaciones que ustedes hacen (...) empiezan a incidir en mi historia de vida, entonces eso ya es absolutamente enriquecedor (p. 2).

Como puede colegirse, la articulación de la lectura, la escritura y el diálogo acerca de obras literarias produce efectos grupales e individuales, cognitivos, simbólicos y afectivos, al entrecruzarse las historias de vida, las subjetividades, lo íntimo y privado con lo grupal o colectivo. Ahora bien, la función de la lectura y la escritura cobra valor al ser articuladas con el uso de la palabra, con el diálogo que se produce en el encuentro, tal como lo destacó una integrante:

La conversación entre todas nos ayudó a comprender (...) eso nos ayuda, y eso se volvió como una práctica, un hábito (...) y se vuelve más enriquecedora cuando se lee en grupo, cuando hacemos la socialización (...). El club hacía como una mirada de todo el ciclo vital de la mujer (...) querer hacer memoria de unos momentos especiales (...) la conexión 
con otras personas, o sea, el libro 'Memorias por correspondencia' que me conectó con mi mamá, pero también con parte de mi familia (p. 5).

Aquí se hizo evidente cómo la identificación permite la articulación de las historias de vida reales y ficticias, singulares y universales, en un proceso de simbolización que permite resignificar la propia historia y elaborar aspectos quizás traumáticos derivados de las experiencias dolorosas en la propia historia de vida. En palabras de una integrante del club:

Diáfora ha sido un espacio de encuentro de unas mujeres, todas con diferentes puntos de vista, con sus ideas (p. 3).

A partir del texto El albergue de las mujeres tristes, la misma participante agregó que:

Dentro del albergue se encuentra una nube de emociones y sentimientos que entrelazan las historias de estas mujeres (p. 3).

Refiriéndose a la articulación de las historias reales y ficticias, pero también lo íntimo y lo colectivo, destacó el:

(...) valor de la intimidad que se genera en este espacio (...) intimidad desde conexión de intereses, desde revelaciones (p. 3).

Además, agregó que al ser compartidas no son objeto de rechazo y, por tanto, pueden ser exteriorizadas con facilidad. Por eso afirmó que en el texto anteriormente citado, las mujeres pueden:

(...) sacar y empezar a curar todas esas penas (p. 3).

De ahí que revelara que:

(...) dentro de mi vida he estado en un tipo de albergue, donde he recibido consejos, he dado consejos y también apoyo de personas que están pasando por lo que yo pasé, o acompañándolas en sentimientos nuevos para ambas (p. 3).

Asimismo, otra integrante resaltó el valor de la escucha:

(...) uno aquí se siente escuchado (...) uno lo valora muchísimo. Yo una vez me asusté, como jay juemadre, sí me están prestando atención! (p. 4).
Esta participante también destacó que:

(...) yo escuchaba lo que quería, y para fortuna aquí te hacen caso aunque te equivoques, entonces es un privilegio hacer parte de ese círculo comunicativo (p. 4).

En ese sentido, en el club no solo se escucha lo estrictamente referido a las obras literarias, sino también los comentarios de las participantes que tratan sobre la vida propia. Así lo refirió la misma integrante, quien dijo que:

(...) la compañía de estas mujeres es como la salvación (...) porque venimos a encontrarnos acá, pero estamos constantemente leyendo cómo estamos. Ahorita, cuando me preguntaban que hace rato no nos veíamos, ¿qué va de tu vida? Sí, uno siempre es ¿cómo vas con tus cosas, con tu historia personal?, eso también es muy especial (...). La necesidad de buscar esa compañía y apoyo (...) empezamos a hablar de cosas en común (...) compartir nuestras experiencias (p. 4).

Esta integrante también comentó acerca de la idea de que el club de lectura actúa como una psicoterapia y produce efectos sobre la calidad de vida de las personas, al promover el desarrollo personal y grupal:

(...) este lugar puede ayudarme con ellas [sus propias penas], a que al menos sean compartidas. No creo que el interés sea que se resuelvan, sino compartir emociones, sensaciones, ideas, retos (...) (p. 4).

Aquí se hizo evidente que el interés principal del club no es resolver las penas de cada una, por lo cual es un efecto no previsto. Un comentario de otra integrante ilustra este punto de vista:

(...) uno aquí siente que su voz es escuchada, y también que somos diferentes lecturas (...) yo no entiendo esto muy bien, necesito ir al club, para intentar descifrar un montón de cosas, que de otra manera no podría (p. 5).

De ese modo, la interpretación conjunta e individual permite descifrar aspectos de la propia historia. Por ello, otra integrante comentó, al respecto del texto $\mathrm{El}$ albergue de las mujeres tristes, que allí se encuentra:

(...) socialización, aceptación y apoyo en cada una de ellas (p. 2). 
Luego agregó, articulando su propia experiencia en el club, que:

(...) yo creo que nosotros no hablamos (...) es un compartir. Yo diría que trascendemos de ese conversar, de esas dudas que tenemos, del no entendí, aquí me quedé, aquí me voy a devolver (p. 2).

De ahí que haya destacado la:

(...) función socializadora, pero también de proyección del sujeto, porque (...) hay un tema en la creatividad, de interpretación, y es que uno ve interpretaciones (p. 2).

Esta integrante resaltó que estas interpretaciones, al provenir de otros, pueden ser enlazadas con las propias en un proceso dialéctico.

En síntesis, en el club se promueven procesos de simbolización elaborativa, tal como ocurre en los procesos de psicoterapia, donde no solo se produce una catarsis, sino también una resignificación de la historia, siendo importante el papel o función de lo estético en este proceso de cuestionamiento y simbolización de las experiencias del pasado a partir de la lectura de obras literarias. De modo que lo estético cumple una función de facilitación de la rememoración implicada en el proceso catártico y simbólico, tal como plantea Freud (1907) con el concepto de soborno estético, que permite el despliegue afectivo, burlando la censura interna y el conflicto intrapsíquico, así como los afectos "hiperintensos" paralizantes como el terror.

Categoría 7. Posición política: Fue evidente que la emancipación y la adopción de posiciones políticas favorecen el desarrollo grupal, social y personal, la toma de conciencia social y promueve la crítica social y el empoderamiento frente al machismo que perpetúa la desigualdad social y la marginación de las mujeres (Martín-Baró, Pacheco y Jiménez, 1990). Al respecto, una de las integrantes del club comentó:

(...) es como otra manera de narrarnos (...). Yo creo que esa es una de las experiencias más valiosas que he tenido, porque la experiencia de lectura con las otras es esperar múltiples miradas que, en definitiva, de manera personal no se logra, y es conocer diferentes mundos a través de la lectura y a través de estas mujeres (...). Fuertísimo ver, por ejemplo, mujeres de una misma familia donde la grande ya trabajaba y su hermana se quedaba cuidando a los niños, entonces ya no podía ir al club, porque había asumido la labor de la que había conseguido trabajo, y era una cadena así de mujeres que tenían hijos súper jóvenes (p. 2).

La cita evidencia el hecho de que la población femenina a menudo no puede acceder a estos espacios formativos, debido a que debe ocuparse de realizar las labores del hogar y no dispone de tiempo para su propio desarrollo personal. La misma integrante hizo un comentario que ilustra la idea de que en la actualidad muchas mujeres se encuentran en la misma posición de las mujeres de épocas pasadas:

(...) era muy curioso que en esta época todavía se siguieran viendo cosas que leíamos en los libros, eso lo asociábamos a las mamás, a las abuelas, a las tías, a la misma experiencia de nosotros en pareja o separadas, y era muy cómico eso, siempre nos llevaba a que esto es lo que estamos viviendo ahora en este momento, esto es lo que vivió mi mamá, esto es lo que vivió mi abuela, esto es lo que vivió mi tía (p. 2).

Así pues, el club contribuye a cuestionar el rol y la identidad que se asigna a las mujeres desde lo social, por lo cual promueve el desarrollo personal y profesional de las mujeres, al permitir una resignificación en los encuentros grupales. En síntesis, participar en el club propicia cambios individuales que, a su vez, se articulan con el desarrollo del grupo y de las mujeres en la sociedad, así lo manifestó la misma integrante:

(...) esa dinámica colectiva nos lleva a que cada una, de forma individual, tenga un universo personal que se transforma a través de lo que aquí nos pasa, pues trabaja como en doble vía, nos hace parte de un colectivo, pero también nos hace sujetos diferentes y enriquecidos, renovadas con todo eso que pasa acá (p. 2).

\section{Discusión}

Estos hallazgos evidenciaron que la articulación de la lectura, la escritura y el diálogo acerca de obras literarias sobre temas de mujeres (categoría 2) produce efectos grupales e individuales, cognitivos (categoría 3), simbólicos y afectivos (categoría 4), al entrecruzarse las historias de vida, las subjetividades, las interpretaciones, lo íntimo y privado con lo 
grupal, a la manera de una psicoterapia de apoyo. En este caso, esta se singulariza por las temáticas tratadas, las cuales versan sobre la condición de ser mujer, la soledad y la tristeza, pero también se producen efectos terapéuticos derivados del acompañamiento y la función estética presente en las obras literarias (categoría 5). Se cuestionan los estereotipos sociales en los que han sido encasilladas las mujeres, permitiendo activar procesos de identificación y simbolización que promueven la resignificación de la historia propia (categoría 6) y la toma de conciencia social y posiciones políticas (categoría 7).

Los efectos producidos en el club de lectura pueden compararse con los de una psicoterapia grupal, pues en ambos se utilizan actividades de tipo artístico, como el juego, el dibujo, el teatro, técnicas introducidas por psicoanalistas y psicoterapeutas desde principios del siglo XX, en el marco de los procesos clínicos y las psicoterapias individuales (Klein, 1929; Ovejero, 2012; Widlöcher, 1975). Pero también en dichos contextos se ha utilizado el trabajo con cuentos infantiles, de hadas, tal como aparece en la obra de Bettelheim (1977) o de Kaes (1987), quienes destacan el hecho de que estas obras literarias están construidas a partir del mismo material inconsciente reprimido en los pacientes neuróticos, y que en los niños se actualiza al articular los cuentos con su propia historia de vida de forma espontánea.

Al respecto, la tradición de utilizar las obras literarias para comprender la psicología del ser humano en el proceso clínico, surge desde el psicoanálisis, la psicología analítica (Jung, 1982) y la psicología humanista (Neira, 2014). Por tal razón, se presentan los primeros historiales clínicos de las experiencias psicoanalíticas de Freud (1895), consignadas en el texto Estudios sobre la histeria. Este autor recuerda las fuertes críticas recibidas desde la ciencia médica y psicológica por el estilo literario, novelesco, con el que presenta estos casos clínicos, que fueron catalogados como un cuento científico. Por ello, Freud (1908) formula la idea de que en los casos clínicos se halla una "novela familiar del neurótico", estableciendo así tempranamente un puente que articula la psicología clínica con las obras literarias, como las novelas (Freud, 1907; Ovejero, 2007a; Ovejero, 2007b, c; 2012).

Es que, además de aportar al campo clínico, Freud realiza aportes para comprender las dinámicas grupales y sociales, tal como se observa en el texto $E I$ múltiple interés del psicoanálisis, en el que recuerda los aportes del psicoanálisis a diversas disciplinas científicas, entre las cuales destacan aquellas que otorgan especial importancia a la interacción, al vínculo, a lo social (Freud, 1913; Ovejero, 2007b, c). El interés por los fenómenos psicológicos humanos (diferentes a los síntomas neuróticos), Ileva a Freud a estudiar fenómenos comunes a todos los seres humanos, tales como el chiste (1905b), el humor (1927), los sueños (1900), los actos fallidos, lapsus linguae, olvidos, entre otros (1901). Dichos fenómenos no se consideran patológicos, aun cuando surgen del mismo conflicto intrapsíquico producido entre los aspectos más pulsionales del ser y los éticos y morales, que provienen de la cultura e intentan facilitar la inserción del sujeto en lo social (Ovejero, 2007b; 2012; Pérez-Álvarez, 1992).

Por esta razón, los clínicos también buscan explicaciones sobre los fenómenos psíquicos en otras dimensiones del paciente, más allá de su sintomatología, explorando sus sueños o chistes, entre otras formaciones del inconsciente, según la expresión de Lacan (1966/1953), quien considera que el inconsciente está estructurado de forma semejante al lenguaje, y se expresa en metáforas y metonimias. En estos casos (la lectura de la obra literaria), el conflicto intrapsíquico entre las tendencias pulsionales de la instancia psíquica denominada el ello y las exigencias morales del superyó, que demandan la renuncia de la satisfacción pulsional de orden sexual y destructivo, encuentra nuevas formas de solución no patológicas (Freud, 1919; Lacan, 1963).

$\mathrm{Si}$ bien en estas obras literarias se recrean escenas de angustia que despliegan afectos displacenteros, como el horror o el terror, pues retorna de lo reprimido parte del contenido inconsciente actualizado por la realidad ficticia de la obra literaria, estos afectos no producen el efecto de parálisis de la motricidad, ni de los procesos asociativos de pensamiento, ni de las funciones cognitivas en general, y en cambio se experimenta una ganancia de placer, gracias al matiz menos peligroso que ofrece lo irreal de la fantasía, de la ficción, de la ilusión que se despliega en la lectura de la obra (Freud, 1919; Lacan, 1963).

Ahora, para que pueda crearse esta escena fantasmática en el lector, es necesario que se activen los mecanismos de defensa o destinos pulsionales 
(Freud, 1905a) que permiten el despliegue de la fantasía a partir de la articulación entre la realidad ficticia creada por el autor de la obra y la recreación de la misma en el lector, la cual es semejante en varios individuos. En cada sujeto, la fantasía construida utiliza los mecanismos de defensa de forma diversa, singular, siendo entonces la fantasía de cada lector una construcción estética particular, subjetiva. Esta comparte algunas semejanzas con las fantasías y construcciones estéticas de otros sujetos con los cuales existe algún vínculo simbólico que permite representar la realidad de forma intersubjetiva, grupal, pero también de forma enteramente singular, personal (Freud, 1919; Lacan, 1963).

En estos fenómenos se produce un "soborno estético" (Freud, 1907), el cual hace posible obtener una "ganancia de placer puramente estética" que permite evitar el despliegue afectivo displacentero, aun cuando los temas sobre los cuales se lee, se escribe y se dialoga generen emociones como la ira, la tristeza, entre otras, además de tendencias de agresión vengativa (Freud, 1893; Uribe, 2013a, b). Esto se da porque se trata de novelas cuyos personajes femeninos experimentan situaciones que incluyen la violencia social e intrafamiliar (Uribe, 2009; 2010b) hacia la mujer, lo cual genera sensaciones de soledad, inequidad, injusticia e incomprensión, que se activan por los procesos de identificación hacia los personajes femeninos de las obras, pero también hacia las escritoras de estas; incluso, entre las mismas integrantes se despiertan tales emociones, pero sin ese carácter displacentero o paralizante (Uribe, 2010a).

Ello obedecería a la calidad estética con la que son representados estos dramas femeninos, que "soborna" a los lectores, al hacer pasar al primer plano el aspecto estético, que, sumado al contagio de emociones entre los miembros del grupo, genera un proceso de identificación y un lazo afectivo que promueve la catarsis grupal, la exteriorización compartida de emociones asociadas a las historias ficticias y sus propias historias de vida, más allá de las diferencias individuales y culturales.

Sin embargo, es un hecho innegable que en Medellín, parte de la población femenina no puede acceder a espacios psicoterapéuticos ni formativos, debido a que deben ocuparse de las labores del hogar y no disponen de tiempo para su propio desarrollo personal. En ese orden de ideas, se resalta que el club permite cuestionar el rol y la identidad que se asigna a las mujeres desde lo social, desde los estereotipos que circulan y se perpetúan en distintos espacios sociales. Este club de lectura se convierte, entonces, en una fuerza contraria que promueve el desarrollo personal y profesional de las mujeres, al cuestionar la propia identidad y permitir una resignificación, en el marco de encuentros grupales en los que se despliegan procesos psíquicos que facilitan la cohesión grupal y la identificación entre sus miembros, tal como ocurre en una psicoterapia grupal.

En síntesis, participar en el club permite cambios individuales que a su vez se articulan con el desarrollo del grupo y de las mujeres en la sociedad. Por esta razón, el Estado colombiano debería interesarse por el estudio de los fenómenos psicosociales que ocurren en estos espacios grupales, en los cuales los propios actores de los fenómenos investigados aportan los datos a partir de los cuales pueden crearse nuevas teorías que amplían el panorama de la ciencia (Taylor y Bogdan, 1984). Asimismo, deberían ser promovidos y estudiados por los científicos de las ciencias sociales, pues es un hecho que dentro de la tradición académica, las dinámicas y las costumbres de estos grupos humanos no han sido considerados objetos de estudio clásicamente.

\section{Referencias}

Bettelheim, B. (1977). Psicoanálisis de los cuentos de hadas. Barcelona, España: Crítica.

Chartier, R. (1993). Libros, lecturas y lectores en la Edad Moderna. Madrid, España: Alianza.

Chartier, R. (2000). Las revoluciones de la cultura escrita. Barcelona, España: Gedisa.

Chartier, R. (2001). Lecturas y lectores "populares" desde el Renacimiento hasta la época clásica. En G. Cavallo y R. Chartier (Comps.), Historia de la lectura en el mundo occidental (pp. 469493). Madrid, España: Taurus.

Freud, S. (1983). Sobre el mecanismo psíquico de los fenómenos histéricos. En J. Strachey (Ed.), J. L. Etcheverry y L. Wolfson (Trads.), Obras completas (Vol. II, pp. 27-44). Buenos Aires, Argentina: Amorrortu. 
Freud, S. (1895). Estudios sobre la histeria. En J. Strachey (Ed.), J. L. Etcheverry y L. Wolfson (Trads.), Obras completas (Vol. II, pp. 1-26). Buenos Aires, Argentina: Amorrortu.

Freud, S. (1900). La interpretación de los sueños. En J. Strachey (Ed.), J. L. Etcheverry y L. Wolfson (Trads.), Obras completas (Vols. IV y V, pp. 1-707). Buenos Aires, Argentina: Amorrortu.

Freud, S. (1901). Psicopatología de la vida cotidiana. En J. Strachey (Ed.), J. L. Etcheverry y L. Wolfson (Trads.), Obras completas (Vol. VI, pp. 1-285). Buenos Aires, Argentina: Amorrortu.

Freud, S. (1905a). Personajes psicopáticos en el escenario. En J. Strachey (Ed.), J. L. Etcheverry y L. Wolfson (Trads.), Obras completas (Vol. VII, pp. 273-299). Buenos Aires, Argentina: Amorrortu.

Freud, S. (1905b). El chiste y su relación con lo inconsciente. En J. Strachey (Ed.), J. L. Etcheverry y L. Wolfson (Trads.), Obras completas (Vol. VI, pp. 1-224). Buenos Aires, Argentina: Amorrortu.

Freud, S. (1907). El creador literario y el fantaseo. En J. Strachey (Ed.), J. L. Etcheverry y L. Wolfson (Trads.), Obras completas (Vol. IX, pp. 123137). Buenos Aires, Argentina: Amorrortu.

Freud, S. (1908). La novela familiar de los neuróticos. En J. Strachey (Ed.), J. L. Etcheverry y L. Wolfson (Trads.), Obras completas (Vol. IX, pp. 213221). Buenos Aires, Argentina: Amorrortu.

Freud, S. (1913). El interés por el psicoanálisis. En J. Strachey (Ed.), J. L. Etcheverry y L. Wolfson (Trads.), Obras completas (Vol. XIII, pp. 165192). Buenos Aires, Argentina: Amorrortu.

Freud, S. (1919). Lo ominoso. En J. Strachey (Ed.), J. L. Etcheverry y L. Wolfson (Trads.), Obras completas (Vol. XVII, pp. 215-252). Buenos Aires, Argentina: Amorrortu.

Freud, S. (1921). Psicología de las masas y análisis del yo. En J. Strachey (Ed.), J. L. Etcheverry y L. Wolfson (Trads.), Obras completas (Vol. XVIII, pp. 63-136). Buenos Aires, Argentina: Amorrortu.

Freud, S. (1927). El humor. En J. Strachey (Ed.), J. L. Etcheverry y L. Wolfson (Trads.), Obras completas (Vol. XXI, pp. 153-162). Buenos Aires, Argentina: Amorrortu.
Jung, C. (1982). Formaciones de lo inconsciente. Barcelona, España: Paidós.

Kaes, R. (1987). La substancia del cuento. En K. R. Perrot J. et al. (Comps.), M. Fernández (Trad.), Contes et divans, les fonctions psychiques des oeuvres de fiction (pp. 1-17), Paris, France: Dunod.

Klein, M. (1929). La personificación del juego en los niños. En Obras completas. Contribuciones al psicoanálisis (Vol. II, pp. 191-200). Buenos Aires, Argentina: Paidós.

Lacan, J. (1963). El seminario de Jacques Lacan. Libro 10. La angustia. Buenos Aires, Argentina: Paidós.

Lacan, J. (1966/1953). Función y campo de la palabra y del lenguaje en psicoanálisis. En T. Segovia (Trad.), Escritos 1 (pp. 231-309). México DF, México: Siglo XXI.

Martín-Baró, I., Pacheco, G. y Jiménez, B. (1990). Ignacio Martín-Baró (1942-1989): Psicología de la liberación para América Latina. Guadalajara, México: Universidad de Guadalajara.

Neira, S. (2014). Literatura y terapia. Monterrey, México: Universidad de Monterrey.

Ovejero, A. (2007a). Psicología social y literatura: la cuestión del canon. En Simposio Psicología Social y Literatura. Cádiz, España: X Congreso Nacional de Psicología Social.

Ovejero, A. (2007b). Sigmund Freud: Reflexiones sobre una historia de vida. Encuentros en Psicología Social, 4, 41-51.

Ovejero, A. (2007c). Una aproximación a la psicología social del psicoanálisis: ¿Es el psicoanálisis una ciencia, una mitología o una impostura? Encuentros en Psicología Social, 4, 52-63.

Ovejero, A. (2008). Algunas reflexiones sobre la relación entre la Psicología Social y la Literatura. Atenea Digital, 13, 225-235.

Ovejero, A. (2009). Lectura literaria y construcción del sujeto moderno. En A. Ovejero (Coord.), Simposio Psicología Social y Literatura: La Construcción de la Subjetividad. Tarragona, España: XI Congreso Nacional de Psicología Social. 
Ovejero, A. (2012). Lo que la literatura puede aportar a la psicología social. OCNOS, 8, 7-20. https://doi.org/10.18239/ocnos_2012.08.01

Pérez-Álvarez, M. (1992). Ciudad, individuo y psicología: Freud, detective privado. Madrid, España: Siglo XXI.

Piaget, J. (1971). Psicología y Pedagogía. Barcelona, España: Ariel.

Serbia, J. (2007). Diseño, muestreo y análisis en la investigación cualitativa. Hologramática, 7(3), 123-146. Recuperado de http:// www.cienciared.com.ar/ra/usr/3/206/n7 vol3pp123_146.pdf

Taylor, S. y Bogdan, R. (1984). Introducción a los métodos cualitativos. Buenos Aires, Argentina: Paidós.

Uribe, N. (2009). El dibujo y la simbolización en algunos casos de maltrato infantil. Una mirada psicoanalítica. Affectio Societatis, 10, 1-12. Recuperado de http:// bibliotecadigital.udea.edu.co/dspace/ bitstream/10495/5675/1/UribeNicolas_2009_ SimbolizacionMaltratolnfantil.pdf

Uribe, N. (2010a). Abuso sexual infantil y administración de justicia en Colombia. Reflexiones desde la psicología clínica y forense. Pensamiento Psicológico, 9(16), 1-23.
Uribe, N. (2010b). Nuevas perspectivas sobre violencia intrafamiliar. Un enfoque psicoanalítico. Affectio Societatis, 7(1)3, 1-18.

Uribe, N. (2013a). Concepciones psicoanalíticas del dibujo en la clínica con niños. Affectio Societatis, 10(19), 48-59.

Uribe, N. (2013b). Inconsciente, palabra e imagen. Reflexiones sobre el uso del dibujo en la clínica. Katharsis, 16, 29-52. Recuperado de http://bibliotecadigital.udea.edu.co/dspace/ bitstream/10495/3800/1/UribeNicolas_2013_ inconscientepalabraimagenreflexionesuso dibujoclinica.pdf

Vasilachis, I. (1992). Métodos cualitativos I. Los problemas teórico-epistemológicos. Buenos Aires, Argentina: Centro Editor de América Latina.

Velasco, H. y Díaz, A. (1997). La lógica de la investigación etnográfica. Madrid, España: Trotta.

Widlöcher, D. (1975). Los dibujos de los niños. Bases para una interpretación psicológica. Barcelona, España: Herder.

Wittmann, R. (2001). ¿Hubo una revolución en la lectura a finales del siglo XVIII? En G. Cavallo y R. Chartier (Comps.), Historia de la lectura en el mundo occidental (pp. 495-537). Madrid, España: Taurus.

Para citar este artículo / To cite this article / Para citar este artigo: Uribe-Aramburo, N. I. (2020). Efectos psicológicos de la literatura en mujeres de un club de lectura en Medellín. Pensamiento Psicológico, 18(1), 127-140. doi:10.11144/Javerianacali.PPSI18-1.eplm 